\title{
Placenta accreta and posterolateral uterine wall rupture in first trimester in multiparous woman with scarred uterus with history of intake of misoprostol and mifepristone: a case report
}

\author{
Surjyatapa Bhattacharjee, Pranoy Nath, Sereesha Rao \\ Corresponding author: Dr. Pranoy Nath, Professor and Head, Dept. Of Obstetrics \& Gynecology, \\ Silchar Medical College and Hospital, Silchar, Assam, India; Email : drnathdas@gmail.com
}

Distributed under Attribution-Non Commercial - Share Alike 4.0 International (CC BY-NC-SA 4.0)

\begin{abstract}
Uterine rupture is a life threatening complication which may lead to significant mortality and morbidity. Posterior wall uterine rupture is a rare presentation especially in the first trimester. Abnormal placental attachment is, similarly, a rare phenomenon, diagnosed chiefly in $3^{\text {rd }}$ trimester. The co-existence of uterine rupture with abnormal placentation in first trimester is extremely rare. Here in, we experienced a case of posterior uterine wall rupture in a 32-year-old gravida 4 para 2 pregnant woman with history of one spontaneous abortion. The patient presented at gestational age of 10 weeks with acute abdomen and severe anemia. She had history of two lower segment caesarean sections. Also, there was history of intake of mifepristone and misoprostol a month back. Ultrasonographic findings were suspicious towards heterotopic pregnancy. However, abdominal exploration revealed posterolateral uterine wall rupture away from the site of lower segment cesarean scar with adherent placenta at the site of scar. Subtotal hysterectomy was done. The patient was discharged 5 days later after transfusion of 4 units packed red blood cells.
\end{abstract}

Keywords: Heterotopic pregnancy, LSCS, placenta accreta.

Hypertensive disorders are the most common Uterine rupture is defined as a disruption of the whole uterine muscle and the visceral peritoneum. Uterine rupture has been observed chiefly at site of previous scar in term pregnancy in post caesarean pregnancies and it is a rare phenomenon in first trimester. It leads to catastrophic results and maternal mortality. ${ }^{1}$ Here we present a case of uterine rupture in a woman with two previous lower segment caesarean sections and history of intake of mifepristone and misoprostol a month back. The woman presented at first trimester with hemoperitoneum, initially diagnosed as heterotopic pregnancy and on laparotomy, posterolateral uterine wall rupture was found away from the site of lower segment cesarean scar and abnormal placentation, which is extremely rare.
Case

A 32 years old woman with gestational age of 10 weeks presented with pain in lower abdomen and severe anemia at a tertiary care hospital in August 2020. She had history of two lower segment caesarean sections, the first was 7 years back and the last one 3 years back. She also had one spontaneous abortion 5 years ago, but there was no history of uterine evacuation or curettage. She had taken urine pregnancy test at home 1 month back, which came out to be positive. Following that, she opted for medical termination of pregnancy for which she took misoprostol and mifepristone on the basis of prescription of a local doctor. There was minimal bleeding per vaginum after intake of the drugs. She repudiated any possibility of trauma.

On examination, the patient was lethargic, tachypneic

Received: $23^{\text {rd }}$ November 2020, Peer review completed: $27^{\text {th }}$ March 2021, Accepted: $30^{\text {th }}$ March 2021.

Bhattacharjee S, Nath P, Rao S. Placenta accreta and posterolateral uterine wall rupture in first trimester in multiparous woman with scarred uterus with history of intake of misoprostol and mifepristone: a case report. The New Indian Journal of OBGYN. 2022; 8(2): 308 - 310. 
and pale with BP 100/60 $\mathrm{mmHg}$ and pulse rate was 104/min. Tenderness and rigidity was elicited all over abdomen. Per vaginal examination revealed bulky tender uterus. Bilateral adnexa could not be assessed properly. Antibiotic, intravenous fluid and other supportive measures were initiated.

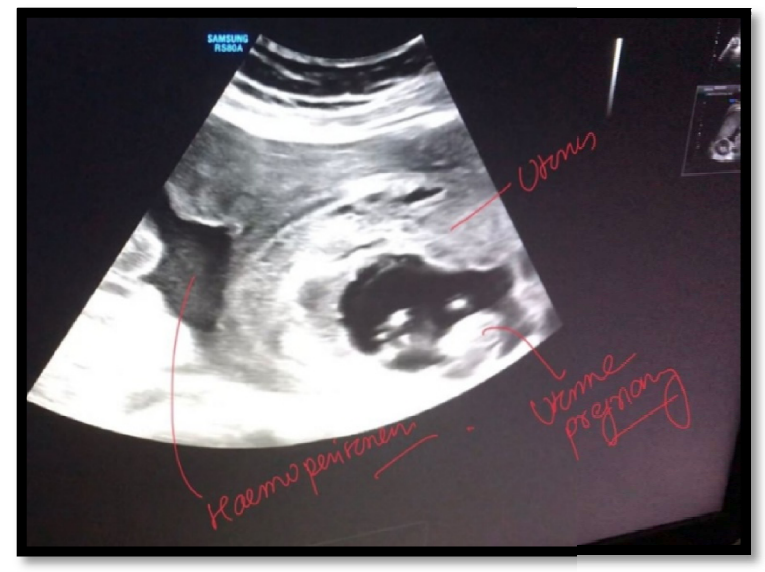

Figure 1: Ultrasound showing intrauterine pregnancy with hemoperitoneum

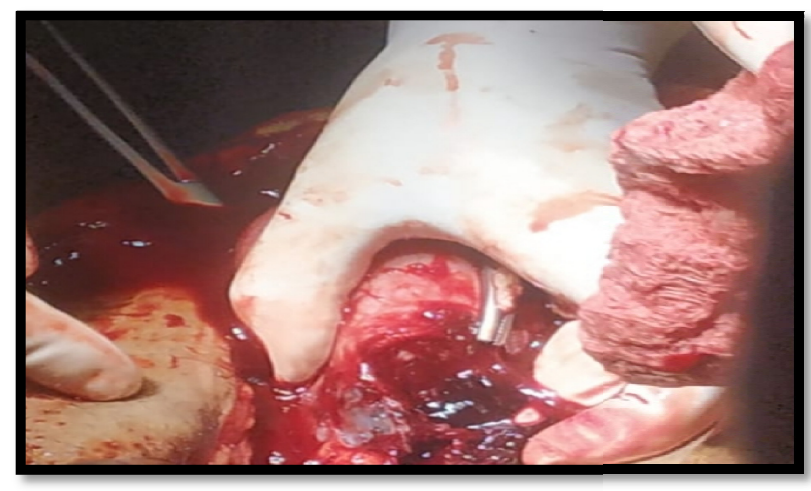

Figure 2: Uterine rupture in posterolateral wall of uterus

Ultrasonography revealed intrauterine pregnancy of 10 weeks with FHR $150 \mathrm{bpm}$ (figure 1). Moderate debrigenous free fluid was noted in peritoneal cavity, suggestive of hemoperitoneum. The suspicion was towards heterotopic pregnancy with rupture of ectopic pregnancy, since live intrauterine pregnancy was visible. Hemoglobin of the patient was found to be $4 \mathrm{gm} \%$. 2 units of packed red blood cell were cross matched and kept ready. The patient party was counseled regarding the need for urgent abdominal exploration.

Exploratory laparotomy was done under general anaesthesia. Hemoperitoneum was observed and around 1.5 L blood with clots were suctioned out. Both the tubes and ovaries were normal, with no evidence of extrauterine pregnancy. Dense adhesions were observed between the bladder wall and the lower segment of uterus in the area of previous scar. The surgery team was called for and adhesiolysis was done by them.

On exteriorization of the uterus, a defect covered with blood clots was noted in the left posterolateral wall of uterus, away from scar site, about $5 \mathrm{~cm}$ in length, extending from the body to the lower segment of uterus (figure 2). The gestational sac with fetus, was noted inside the uterus. On exploration, the fetus was extracted and the placenta was found to be implanted at the site of previous uterine scar. Subtotal hysterectomy was done. Both the tubes and ovaries were preserved. Intra peritoneal drain was kept and abdomen closed in layers after achieving hemostasis.

The patient made a smooth recovery from general anaesthesia and was shifted to post-operative room. She received 4 units of packed red blood cell and the postoperative period was uneventful. She was discharged 5 days later with $\mathrm{Hb} 8.5 \mathrm{gm} \%$.

\section{Discussion}

Uterine rupture generally occurs at the site of previous caesarean scar owing to fibrosis and weakening of myometrium at the site of scar. However, in our case, the rupture was observed in the posterolateral wall, which may be ascribed to the fact that the posterior wall of uterus might have been subjected to excessive stretching and thinning unlike stiff uterine scar that prevented equal stretching. This led to the unusual rupture of the healthy tissue and not the scarred part. ${ }^{2}$

The risk of abnormal placentation is increased many fold in case of previous caesarean delivery. Previous surgical damage interferes with the process of normal decidualisation and disrupts the endometrium-myometrial interface of the uterine wall, leading to abnormal implantation of growing placenta over scar area. The sensitivity of ultrasound in diagnosis of placenta accreta in first trimester is very low $(41 \%)^{3}$

Misoprostol (prostaglandin E1 analog) and mifepristone have been widely used for medical method of termination of pregnancy. However, misoprostol may intensify the risk of rupture in uterus with previous surgery. ${ }^{4}$ In our case, the patient had opted for medical termination of pregnancy around 6 weeks of gestation but she presented with uterine rupture after a month, at the gestational age of 10 weeks. So it is a matter of contemplation whether intake of misoprostol or mifepristone could possibly have lead to this catastrophe. 
The New Indian Journal of OBGYN. 2021 (January-June);8(2)

Fabiana Cecchini et al extracted a total of 76 case reports in the study "first trimester uterine rupture: a case report and literature review" and observed that fifty-three patients out of $76(69.74 \%)$ underwent previous surgery on the uterus. Most women (67.92\%) had a caesarean section, and placenta accreta spectrum (PAS) disorder was found to be the etiology in $77.78 \%$ of cases. Considering the women with history of caesarean section, 4 had history of medical termination of pregnancy with drugs. Myomectomy, hysteroscopic resection of uterine septum, cornual resection etc may also lead to uterine rupture. In patients with unscarred uteri, high parity ( $\geq 4$ births), abnormal placentation, uterine anomalies, curettage may be implicated in uterine rupture. ${ }^{1}$

Uterine rupture in first trimester is rare, dangerous and catastrophic. Clinical signs are not very specific, and need to be distinguished from other abdominal emergencies. Hemoperitoneum and acute abdomen in early gestation is often confused with ruptured ectopic pregnancy and the definite diagnosis is made only on laparotomy. As observed in our case, the initial diagnosis was heterotopic pregnancy (coexistence of intrauterine and extrauterine gestation), but on exploration, it was found to be rupture of posterolateral wall of uterus.

Literature and case reports on the management of uterine rupture in the first trimester are scarce and limited. In early cases, the defect may be repaired and tubal ligation done. However, in advanced cases, hysterectomy may be necessary.

Extent of the tear, desire to preserve future fertility, general condition of the patient etc are the determinants that dictate the choice of surgery. ${ }^{2}$

\section{Conclusion}

Uterine rupture in first trimester is a life-threatening event which may often be misdiagnosed. The chief risk factors include scarred uterus, placenta accreta spectrum, uterine anomaly etc. Posterior wall rupture is rare, hence high degree of clinical suspicion and prompt surgical laparotomy is the only way to deal with this grave situation and hence prevent maternal morbidity and mortality.

\section{Conflict of interest: None. Disclaimer: Nil.}

\section{References}

1. Cecchini F, Tassi A, Londero A, Baccarini G, Driul L, Xodo S. First Trimester Uterine Rupture: A Case Report and Literature Review. International Journal of Environmental Research and Public Health. 2020; 17(8): 2976.

2. Abbas AM, Hussein RS, Ali MN, Shahat MA, Mahmoud AR. Spontaneous first trimester posterior uterine rupture in a multiparous woman with scarred uterus: A case report. Middle East Fertility Society Journal. 2018; 23: 81-3.

3. Jauniaux E, Collins SL, Burton GJ. Placenta accreta spectrum: Pathophysiology and evidence-based anatomy for prenatal ultrasound imaging. Am. J. Obstet. Gynecol. 2017; 218: 75-87.

4. Ghaemi M. Uterine Rupture after Misoprostol Use for Termination of Pregnancy in Second Trimester with Previous Caesarean Section: A Case Report. Crit Care Obst Gyne. 2018; 4(3):14.

\section{Surjyatapa Bhattacharjee ${ }^{1}$, Pranoy Nath ${ }^{2}$, Sereesha Rao $^{3}$ \\ ${ }^{1}$ Post Graduate Trainee, Dept. Of Obstetrics \& Gynecology, Silchar Medical College and Hospital, Silchar, Assam, India; ${ }^{2}$ Professor and Head, Dept. Of Obstetrics \& Gynecology, Silchar Medical College and Hospital, Silchar, Assam, India; ${ }^{3}$ Registrar, Dept. Of Obstetrics \& Gynecology, Silchar Medical College and Hospital, Silchar, Assam, India.}

